\title{
On a digestive ferment contained in the juice of the fig-tree
}

\section{Bouchut}

To cite this article: M. Bouchut (1880) On a digestive ferment contained in the juice of the figtree, Philosophical Magazine Series 5, 10:60, 139-140, DOI: 10.1080/14786448008626906

To link to this article: http://dx.doi.org/10.1080/14786448008626906

曲 Published online: 28 Apr 2009.

Submit your article to this journal $\pi$

Џll Article views: 4

Q View related articles $\sqsubset$ 
In concluding this compendious sketch, I consider it a duty to express my deep gratitude to MM. P. Desains and J. Jansen, who have promoted and encouraged my researches; and I must also record the obliging cooperation of the house of Carpentier, and in particular of M. Guerout, who has directed, with much care and kindness, the construction of my apparatus.-Comptes Rendus de

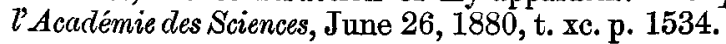

\section{ON A DIGESTIVE FERMENT CONTAINED IN THE JUICE OF THE}

\section{FIG-TREE. BY M. BOUCHUT.}

The researches which I and M. Ad. Wurtz presented to the Academy, on the digestive action of the juice of Carica papaya, and of the digestive ferment (papaine) which it contains, have induced me to see if that was not a fact connected with a general carnivorous property of the latex of many other plants. Special studies, carefully made, in that direction compel me to think so; and now, at least, the thing seems demonstrated by the milky juice of the common fig-tree.

This juice is not very copious, its collection slow and difficult; no one has any great quantity of it. Nevertheless I obtained from Provence a remittance of the latex collected in the month of April - which it is important to remember, as the quality of the juice changes with the more or less advanced state of the regetation; and in the laboratory of $\mathbf{M}$. Wurtz we made some experiments, which have given the following results :-

Five grams of the milky juice, in part coagulated-forming a serous portion, and a white, glutinous, elastic, and perfumed resinous coagulum-were kept, in a glass with 60 grams of distilled water and 10 grams of moist fibrine, at a constant temperature of $50^{\circ} \mathrm{C}$. After some hours the fibrine was attacked, softened; and in the evening it, was digested, leaving a little white residue at the bottom of the glass.

I added successively, in the same glass and the same liquid:first, 10 grams of moist fibrine, which were digested in twelve hours; next, 12 grams, and then 15 , and that eight times at intervals of one or two days, always taking care to keep the vessel at the same temperature. These different additions amounted to no less than 90 grams of fibrine for one month of experiment.

Each quantity of fibrine was digested in less than twenty-four hours, and left a homogeneous whitish residue, which was added to that of the preceding digestion. The solution had a pronounced odour of good broth, without the slightest putridity and with a pleasant smell, due to the resinous coagulum of the fig-tree juice left designedly in the glass.

At the end of a month we discontinued the experiment. The fibrine digestions had not fermented; they retained a savoury smell of digested meat, plus the aroma of the fig-tree resin. Other similar experiments have yielded the same results. They prove 
that there is in the latex of the fig-tree a powerful digestive ferment; and we hope shortly to be able to state what is the composition of the residue and what the nature of this new vegetable pepsine principle which is capable of thus digesting albuminoid substances.-Comptes Rendus de l'Académie des Ściences, 5th July, 1880 , t. xci. p. 67.

\section{OBSERVATIONS ON THE VAPOUR-DENSITY OF IODINE. \\ BY M. BERTHELOT.}

In the abstract theory of gases it is assumed that the simple gases receive simultaneously one and the same increment of total energy and one and the same increment of vis viva of translation when they undergo one and the same change of temperature. This conception translates the experiments of physicists on the specific heat of gases (the law of Dulong and Petit), their expansion by heat (Gay-Lussac's law), and their compressibility (Mariotte's law).

Again, it is concluded from the two latter laws that the density of a gas (that is, the ratio between the weight of a given volume of it and the weight of the same volume of air), taken at the same temperature and the same pressure, is, as a principle, constant. The deviations hitherto observed have been attributed to secondary perturbations.

These three laws have really been demonstrated for three elements only (oxygen, hydrogen, nitrogen) ; they constitute the only scientific foundation on which the physical determination of molecular weights, and consequently the numeration of the atoms, in present theories rests. If for certain elements these laws were to cease to be true, in that case the physical definition of the molecular weights of those elements and that of the number of their atoms would become pure conventions.

Now I have already pointed out that the experiments of MM. Kundt and Warburg on the velocity of sound in mercurial gas were irreconcilable with the whole three fundamental laws above recapitulated (Annales de Chimie et de Physique, 5e série, t. ix. p. 427).

The experiments of M. V. Meyer on the diminution of the gaseous density of iodine and the halogen elements under constant pressure, but at temperatures very remote from one another, are still more opposed to the received laws. These experiments are moreover confirmed and extended by those which M. Troost has just performed on the same body, at a constant temperature but under various low pressures, with the great precision which characterizes him*.

Thus the variation of the vis viva of translation of the molecules of gaseous iodine, under the influence of very high temperatures or of very low pressures, far surpasses the same variation, observed

* Vide infrd, p. 141. 